\title{
Wegener's granulomatosis complicated by diabetes insipidus
}

\author{
N. P. HURST, N. A. DUNN, AND T. M. CHALMERS \\ From the Rheumatic Diseases Unit, Northern General Hospital, Ferry Road, Edinburgh EH5 2DQ
}

SUMMARY We report a case of Wegener's granulomatosis complicated by cranial diabetes insipidus in which no evidence of local sinus erosion or intracranial granuloma was found. Unlike previously reported cases, the diabetes insipidus has not resolved despite successful treatment of the vasculitis. The patient is also unusual in that she had a prolonged 9-month prodromal period of seronegative polyarthritis before the appearance of typical systemic vasculitis and granuloma formation.

Diabetes insipidus is an uncommon complication of Wegener's granulomatosis. It may be due either to erosion of granulation tissue from the sinuses into the hypothalamus or to intracranial granuloma formation. We report the case of a woman with Wegener's granulomatosis who developed cranial diabetes insipidus and in whom no evidence of frank sinus destruction was found. The patient differs from the few previously reported cases in that the diabetes insipidus has persisted despite successful treatment of systemic disease.

\section{Case report}

A 47-year-old district nurse developed an inflammatory seronegative nonerosive polyarthritis, which was treated with nonsteroidal anti-inflammatory drugs. Three months after the onset of arthritis she had a prolonged episode of serous otitis media and deafness treated with antibiotics. The clinical and serological findings remained unchanged for 6 months. She then developed acute sinusitis requiring antral lavage, which was followed by a severe disabling exacerbation of her arthritis with widespread synovitis, necrotising cutaneous vasculitis, oral ulceration, episcleritis, pleuritic chest pain, polyuria, and polydypsia in excess of 4 litres per day. On admission to hospital no additional features were noted and ear, nose, and throat (ENT) examination was normal.

The haemoglobin concentration was $11.2 \mathrm{~g} / \mathrm{dl}$, with a normochromic normocytic film; the white cell count, differential, and platelet count were normal.

Accepted for publication 3 November 1982. Correspondence to Dr T. M. Chalmers.
The ESR (Westergren) was $92 \mathrm{~mm} / \mathrm{h}$. Rheumatoid factor was positive at a titre of 1 in 160, but antinuclear antibody was not detected, and serum complement levels were normal. Plasma electrolytes were normal, blood urea was $6.5 \mathrm{mmol} / \mathrm{l}$, and the plasma osmolality $292 \mathrm{mosmol} / \mathrm{kg}$. Urine analysis showed haematuria, red cell casts, a trace of proteinuria, and a specific gravity of 1000 . A chest $x$-ray revealed a left apical opacity of $2.5 \mathrm{~cm}$ diameter which had not been present 3 months previously. $X$-rays of skull, hands, and feet were normal, but sinus $x$-rays showed slight thickening of the right maxillary sinus.

ENT examination under anaesthesia revealed no significant abnormality, but biopsies of macroscopically normal sinus mucosa confirmed the presence of typical Wegener's granulomatous vasculitis with giant cells. Treatment with prednisolone and cyclophosphamide was initiated pending the results of histological examination. Polyuria and polydypsia became increasingly troublesome, with plasma osmolality rising well above the normal range together with a very dilute urine. A desmopressin test, without prior water deprivation, confirmed cranial diabetes insipidus (Table 1) and regular treatment with vasopressin (DDAVP) was commenced. After 9 months of treatment with maintenance cyclophosphamide and low-dose corticosteroids, and despite complete remission of all features of systemic disease, the diabetes insipidus has not resolved, and daily intranasal DDAVP has been required. A CT scan has shown no evidence of a local destructive lesion, and tests of pituitary function are normal (Table 1). 
Table 1 Pituitary function tests

\begin{tabular}{|c|c|c|c|c|c|}
\hline & & \multicolumn{2}{|c|}{$\begin{array}{l}\text { Plasma } \\
\text { osmolality } \\
\text { (mosmol/kg) }\end{array}$} & $\begin{array}{l}\text { Urine } \\
\text { osmolality } \\
\text { (mosmol/kg) }\end{array}$ & $\begin{array}{l}\text { Urine volume } \\
(\mathrm{ml} / \mathrm{h})\end{array}$ \\
\hline \multicolumn{6}{|c|}{ Desmopressin test } \\
\hline \multicolumn{5}{|c|}{ DDAVP intra- } & 240 \\
\hline \multicolumn{6}{|c|}{2 hours after } \\
\hline \multicolumn{2}{|c|}{$2 \mu \mathrm{g}$ DDAVP } & 297 & & 521 & 30 \\
\hline \multicolumn{6}{|c|}{ Anterior pituitary function tests } \\
\hline \multicolumn{6}{|c|}{$\begin{array}{l}\text { Anterior pituitary function tests } \\
\text { (normal) }\end{array}$} \\
\hline TSH & \multicolumn{2}{|c|}{$1 \cdot 1 \mathrm{IU} / 1$} & \multicolumn{2}{|c|}{$(<5 \cdot 7)$} & \\
\hline Serum T3 & \multirow{2}{*}{\multicolumn{2}{|c|}{$\begin{array}{l}99 \mathrm{nmol} / 1 \\
203 \mathrm{mU} / \mathrm{l}\end{array}$}} & \multicolumn{2}{|c|}{$(45-145)$} & \\
\hline Prolactin & & & \multirow{2}{*}{\multicolumn{2}{|c|}{$\begin{array}{l}(60-380) \\
(<26)\end{array}$}} & \\
\hline FSH & \multicolumn{2}{|c|}{$56 \mathrm{IU} / 1$} & & -Pos & $\begin{array}{l}\text { menopausal } \\
\text { ls }\end{array}$ \\
\hline LH & \multicolumn{2}{|c|}{$57 \mathrm{IU} / 1$} & \multicolumn{2}{|c|}{$(<25)$} & $\begin{array}{l}\text { levels } \\
\text { - Postmenopausal } \\
\text { levels }\end{array}$ \\
\hline
\end{tabular}

TSH $=$ thyroid-stimulating hormone. $\mathrm{T} 3=$ tri-iodothyronine. FSH $=$ follicle-stimulating hormone. $\mathrm{LH}=$ buteinising hormone.

\section{Discussion}

Wegener's granulomatosis is characterised by granulomatous lesions of the upper and lower respiratory tract, necrotising vasculitis, and glomerulonephritis, and the patient often presents with upper respiratory symptoms. ${ }^{1}$ It is to be distinguished on clinical and pathological grounds from lymphomatoid granulomatosis, polyarteritis nodosa, Churg-Strauss vasculitis, and lethal midline granuloma. Joint symptoms occur in up to $60 \%$ of cases and are usually mild, frank synovitis being rare. ${ }^{2} \mathrm{Up}$ to $50 \%$ of cases also have involvement of the nervous system. ${ }^{1}$ Though the disease was formerly considered to be always fatal, the prognosis has been markedly improved by the introduction of cytotoxic agents, particularly cyclophosphamide. ${ }^{1}$

Our patient illustrates 2 unusual features. Diabetes insipidus associated with Wegener's granulomatosis has previously been reported in only 4 patients. ${ }^{3} \mathrm{Al}-$ though local extension of granuloma into the hypothalamus from the sinuses may be responsible, we could find no evidence of this on $x$-ray or CT scan of the skull, and there was no evidence of anterior pituitary dysfunction. The lesion was thus localised and probably due to vasculitis or to local granuloma formation. A previously reported case of diabetes insipidus complicating Wegener's granulomatosis responded well to cyclophosphamide therapy. ${ }^{3}$ The lack of response in our patient suggests that frank infarction had occurred.

A further unusual feature is the 9 months' history of preceding frank polyarthritis. Although polyarthritis can accompany Wegener's granulomatosis it is usually mild and does not precede the development of other symptoms by more than 3 months. ${ }^{4}$ The diagnostic criteria for rheumatoid arthritis do not specifically exclude Wegener's granulomatosis, and diagnostic confusion with rheumatoid arthritis may occur. ${ }^{4}$ This is clearly a problem in the early stages of the disease when classical features of Wegener's granulomatosis may be absent, and many patients have weakly positive tests for rheumatoid factor. Our case clearly underlines the diagnostic value of respiratory sinus mucosal biopsy even when the mucosa is macroscopically normal, and we believe that earlier biopsy of our patient could have provided the diagnosis before the onset of life-threatening systemic disease.

\section{References}

1 Hoekstra J A, Fauci A S. The granulomatous vasculitides. Clin Rheum Dis 1980; 6: 373-88.

2 Fauci A S, Wolf S M. Wegener's granulomatosis: studies in 18 patients and a review of the literature. Medicine (Baltimore) 1980; 52: 535-61.

3 Haynes B F, Fauci A S. Diabetes insipidus associated with Wegener's granulomatosis successfully treated with cyclophosphamide. N Engl J Med 1978; 299: 764.

4 Pritchard M H, Gow P. Wegener's granulomatosis presenting as rheumatoid arthritis (two cases). Proc $R$ Soc Med 1976; 65: 501-4. 